\title{
THE ONE MINUTE PAPER AND ASSESSMENT INNOVATION AT THIRD LEVEL: A TEACHING NOTE
}

\author{
Edel Barnes \\ University College Cork
}

\begin{abstract}
This paper takes up the increasingly contentious subject of how teachers know and assess what students at third level have learned and know. While research into teaching and learning is developing in institutions of higher education nationally, the extant literature is not extensive. Specifically, instruments such as the One Minute Paper (OMP), which this study has as its focus, are not widely used, even though it is both straightforward to implement and well received by students where research has been undertaken. This study constitutes a teaching note that reflects on the usefulness of introducing the OMP to enhance the effectiveness of lectures in terms of developing student learning. It concludes that the innovation contributes substantially to students' ability to develop their own sense of meaning and identification with lecture topics and, in this case, resulted in a noteworthy improvement in student performance in summative examinations.
\end{abstract}

\section{INTRODUCTION}

There is an increasing and welcome recognition in both the education literature and in practice that teaching, regardless of discipline, should be about studentcentred learning (for example, Angelo and Cross, 1993; Biggs, 1999; Lyons, Hyland and Ryan, 2002; Berry, 2004; Bok, 2006). Students should be actively involved and should strive to engage more holistically in the learning process, taking new theories and insights on board, revisiting, reflecting, debating, conversing, weighing, balancing, growing in knowledge and understanding, and ultimately constructing their own sense and meaning. There is probably less widespread acceptance that practitioners should engage in an evaluation of that learning process. However, if traditional approaches to assessment fail to serve our students best, one cannot persist simply because such modes are pervasive or because they reflect the established signature pedagogies of our discipline. The community of 
Barnes

learners, particularly at tertiary level, is increasingly diverse and nowadays includes full-time and part-time students, school-leavers and mature students, distance learners and on-campus constituencies. Many will come from backgrounds that might be considered 'alternative' or 'disadvantaged' in the context of traditional schooling norms. An open-minded, flexible, inclusive philosophy of teaching, learning and assessment must take all these contextual factors into account, and teaching and assessment design must reflect the variety of characteristics, strengths and difficulties that typify learners as a whole.

One startling result of recent reviews of education in the United States and in Europe is the lack of hard evidence of student learning (Cochran-Smith and Zeichner, 2005; Kuh, Kinzie, Schuh, Whitt and Associates, 2005; Teichler, 2007). Zeichner (2005) states flatly that student learning has been largely neglected in teacher education research. Bok (2006) finds that college students lack critical thinking skills and the ability to make sound judgments beyond a naïve epistemology. Not surprising, calls are being made to launch rigorous new assessments of college students in the US and in Europe (Kuh, 2007; Shulman, 2007; Teichler, 2007). In many European countries, the relationship between higher education and the world of work and how this gap is bridged in practice is poorly understood (Teichler, 2007). Complicating this situation is the difficulty of uncovering what it takes to engage students in self-inquiry and how to teach such skills. Kuhn (2005) believes that students must have not only the skills but also the opportunity to engage in increasingly complex forms of inquiry and to grow in epistemological understanding of the nature of knowledge, especially the metacognitive task of knowing how they know.

This paper takes up the issue of how to develop students' skills in active selflearning, together with assessing what students have learned and know. It describes a class project whereby students are asked to explicitly identify what they have come to know and what they still do not understand, in the context of lecture topics. Essentially the study hopes to determine whether introducing the One Minute Paper (OMP) - a classroom assessment technique that asks students to document what they have understood and also areas of troublesome knowledge - is useful in enhancing the effectiveness of lectures in terms of developing student learning. The remainder of the paper is structured as follows. The literature and evidence that exists on the use of and perceptions of the OMP are initially summarised. The next section explains and describes my choice of classroom assessment technique (CAT), that is, the One Minute Paper (OMP), together with the motivations for its introduction. The subsequent section describes the sample group and the teaching design. An analysis of the findings of the study follows, together with some reflection thereon. The final section summarises and concludes.

\section{THE LITERATURE}

Biggs (1999) coined the term 'constructive alignment' as a teaching paradigm, a term that has become one of the most influential ideas in higher education. Alignment is about getting students to take responsibility for their own learning 
and establishing trust between teacher and student. The onus is on teachers to create a teaching environment that is supportive and encouraging of students and which facilitates them in active mental engagement with lecture topics. There are two parts to constructive alignment: students construct meaning from what they do to learn, and teachers align the learning activities with the stated learning outcomes. Thus, teachers must have a clear idea of what it is they want their students to know and understand, communicate these learning outcomes clearly and design teaching activities with that objective in mind. Therefore, learning activities, learning outcomes and assessment should be aligned and consistent. It has been suggested that alignment is essentially a question of honesty in communication between teacher and student that establishes trust in an environment that is conducive to students managing their own learning (Biggs, 2003). Thus, constructive alignment encourages clarity in teaching and curriculum design, and transparency in linkages between learning and assessment. Just as teaching design needs to support student participation it must also be flexible and subject to modification as the teacher reflects on his/her delivery.

The objective of this study was to document the effectiveness of this learning paradigm. Stated succinctly, the aim was to assess my ability to achieve this constructive alignment by communicating learning outcomes for a financial management module clearly to students, engaging them actively in the learning process by introducing a simple, easy to administer classroom assessment technique, which I refer to as the One Minute Paper (OMP), and reflecting on any improvements in understanding and learning that developed from that process.

One of the most pressing issues in teacher research regards the rigor of the work and its connection to other research in the field. Berry (2004) comments:

One of the major challenges for self-study of teacher education practices continues to involve finding ways to remain true to itself in communicating the particularities of experience while at the same time drawing out generalisable knowledge that can be widely available to others (Berry, 2004, p. 1328).

In consequence it is interesting to query what has been learned from application of the classroom assessment techniques (and the OMP in particular) in practice, and to posit how this work might be useful to others to advance their own teaching and learning.

The extant literature on the pervasiveness and efficacy of the OMP is not large. Where it has been used, both students and teacher practitioners regard it positively (Stead, 2005). However, such literature as exists relates largely to the US and to a lesser extent to the UK. Furthermore, the literature tends to focus generally on descriptions of the OMP in various contextual situations but speaks little as to how the test is actually applied and/or to the rich data sets that it has the potential to create.

Stead (2005) reviews the literature on the use and perception of the OMP and documents evidence of both extent of use and student opinion. His paper documents awareness that the OMP is widely applicable, easy to use, requires little or no technology and relatively little time and effort to incorporate into teaching and 
assessment design. However, perversely, the OMP appears to be rather sparsely utilised for both Stead's sample and by other surveys cited by the author. While the OMP is recognised as a good learning tool by teacher and learner alike, yielding improved performance benefits for students and timely valuable feedback for teachers, it appears that a significant majority of teacher practitioners are either not aware of the technique or have misconceptions regarding the necessary requirements of time and effort. Furthermore, students are liable to tire of the technique if used too frequently - Stead (2005) documents rapidly declining completion rates over a given semester of usage.

At practitioner level, there appears to be some interdisciplinary variation in usage; economists tend to use the tool relatively little, although the OMP has been used to an extent in the accounting and auditing field of study. Almer, Jones and Moeckel (1998), for example, compare the performance of 867 introductory accounting students and find that regular completion of the OMP was associated with significantly improved student performance in tests where there was some element of subjective assessment, independent of student ability. McElroy and Coman (2002) report supporting evidence of performance improvements for introductory managerial accounting students, while Chizmar and Ostrosky (1998) document improvements in performance in multiple choice tests (which are comprised largely of objective material) taken by their sample of 571 economics students. In general, however, application rates for the OMP were found to be biased towards those who are pre-disposed to innovations in teaching and learning practice generally.

To date there has been little, if any, analysis of the OMP's use in the context of higher education in Ireland of which I am aware. As a prelude to its introduction for the purposes of this study, the University College Cork (UCC) academic community was surveyed through circulation of an online weblink survey that solicited information regarding knowledge of CATs, specifically the OMP, reasons why it wasn't utilised, respondent's disciplinary area and extent of teaching experience. The response rate was 211 academic staff members, or approximately 12 per cent. In total 50 users ( 24 per cent) utilise the OMP technique, while 159 (76 per cent) are non-users. Reasons for its non-use range from lack of knowledge of the technique ( 108 respondents or 67 per cent) to concerns about time requirements and class size ( 15 respondents or 9.3 per cent), availability of other sources of student feedback ( 29 respondents or 18 per cent) and utilisation of other forms of active learning (33 respondents or 20.4 per cent), these latter to include in-class discussion, blackboard discussions and group work. Across the range of respondents, 64 separate disciplines were represented, 5 respondents derived from Accounting/Finance and 9 from Economics. There was no significant link between use of the OMP and teaching experience, albeit those new to teaching were more likely to use the OMP.

Membership of the Irish Accounting and Finance Association (IAFA) was the basis for a survey of institutes of higher education nationally. In total, there were 99 responses, or approximately 72 per cent, of which 3 (96) respondents were users (non-users) of the OMP. Of those who responded, 69 (approximately 70 per cent) had never heard of the assessment technique, 15 (15.2 per cent) considered it too 
time-consuming, 9 (9.1 per cent) and 6 (6 per cent) had other feedback sources or utilised other learning tools respectively, such as blackboard and in-class questions. Across the disciplines 43 (43.4 per cent) of respondents teach Financial Accounting, 36 (36.4 per cent) teach Managerial Accounting, 3 ( 3 per cent) teach Taxation, 12 (12.2 per cent) teach Finance and 5 (5 per cent) teach Auditing. In total 14 separate institutions were represented in the survey, split evenly between universities and institutes of technology. As a whole, therefore, there appears to be little recognition of the role that classroom assessment techniques such as the OMP can play in ascertaining the extent of student learning and in offering valuable sources of feedback on learning to students and teacher alike. In consequence it is considered that a teaching note that reflects on the effectiveness of the OMP in developing student learning might constitute a useful increment to the literature at this time. If the OMP represents a positive feature of teaching design, there may be potential implications on foot of this self-study for the future of accounting and financial management education, as the discipline that represents the focus of this study.

\section{CLASSROOM ASSESSMENT TECHNIQUES: THE ONE MINUTE PAPER}

Every teacher is keen to draw his/her learners into the subject, to engage with them and to interest them in the subject matter. To develop learning is exciting and encourages greater enthusiasm and involvement. However that journey is less rewarding when there is failure to facilitate that development of learning. How one determines whether that desired increment in learning is achieved is thus critical to the success of a practitioner's teaching design. Classroom assessment techniques (CATs) provide both teacher and learner with evidence of learning (or not), evidence that is important in all learning contexts but vital when one is charged with bringing a subject or discipline to a group of learners with no prior exposure to or experience in the field, such as the focus group for this study. Any teacher can cover material throughout a teaching period but to engage students actively provides scope for them to make their own meaning of new knowledge, to make it their own. This is a process rather than an action with an instantaneous product. CATs facilitate a stream of checks and balances, an ongoing answer to the question of what it is our students come to know and whether they are making their own sense of meaning on the learning journey. Critically, CATs facilitate feedback, which is formative, immediate and useful, and they give teachers 'information to navigate by, feedback to guide the continual small adjustments and corrections needed to keep student learning on course' (Angelo and Cross, 1993, p. 26). CATs also facilitate the integration of teaching and learning with assessment. This (informal) assessment enables a practitioner to revisit his/her teaching design, consistent with Biggs' (1999) 'constructive alignment' to ensure that students' learning experiences are compatible with desired learning outcomes: those key points or concepts that are important for our learners know and understand.

CATs are tools that come in a variety of shapes and formats and certain tools will work well with some groups of learners and less well with others. Angelo and 
Cross (1993) define CATs as 'instruments that faculty can use to find out how much, how well, and even how students are learning what they are trying to teach' (Angelo and Cross, 1993, p. 25, emphasis added). The most effective and therefore useful CATs are context-sensitive (relate to a clearly defined topic for a specific group of learners), are flexible (can be adapted for use in a variety of situations), can potentially make a difference (relate to a teaching design that can be altered), are beneficial for both teacher and learners, are simple and straightforward both to administer and to analyse, and are valid in that they enhance specific learning objectives/content/skills. The decision to use a particular CAT requires a teacher to plan - this involves choosing the focus group, deciding on the class meeting and selecting the particular CAT to be used. My choice of CAT was made in the context of students with no prior exposure to financial management concepts or to in-class formative assessment techniques. It draws from features of both the One Minute Paper (OMP) and the Muddiest Point (MP) tools, and asks students to reply to two questions:

- What was the most important thing you learned and

- What was/is the main question remaining at the conclusion of the class?

The objective was to encourage students to investigate the extent of their own learning, and to provide formative feedback for myself as teacher to inform subsequent lecture content.

Implementation requires a teacher to let students know in advance what he/she is going to do, to let them know that he/she is asking for information that will assist him/her as a teacher in optimising their learning opportunities, and to inform them how much time they will have to undertake the CAT. It also involves taking cognisance of the time that will be necessary to read the responses and to analyse them. Ideally a practitioner will have time to read and analyse responses as early as possible after a class, typically each response will require just a few minutes to read through and appreciate. If CATs are to be truly effective as a learning-enhancement tool there is a need to respond, to 'close the feedback loop' (Angelo and Cross, 1993, p. 30). This is essentially a question of letting learners know what you as teacher learned from the CAT exercise, and explaining how you will use that information, in other words, what difference their responses will make to your teaching enactment/design. If use of CATs is to qualify as a learnercentred strategy, learners need to be told that their participation in the assessment can and will make a difference to how you teach and in consequence to how they learn. Of course there is also potential for learners themselves to change their behaviour to improve their own learning, and the CAT responses, together with a teacher's reflection-on-action, may highlight some such possible changes.

Teaching and learning are or should be shared activities, the joint responsibility of both teacher and learner. My plan was to consider the concepts that were continuing to cause understanding blockages, and in particular those 'muddiest points' that were causing difficulty for a number of learners. This reflection would prompt me to revisit these points in preparation for the immediately following lecture; to reconsider my approach to explanation and illustration; to ponder what potential barriers to understanding might have arisen; and to explore alternative 
'entry points' to these concepts (constructive alignment). Above all my objective was to achieve teacher-student appreciation of areas of problematic learning and to remain with these muddiest points until satisfied that the barriers to understanding had been overcome. My hope was that in the OMPs submitted at the end of the subsequent lecture, these important concepts would appear in the learner responses to the first question regarding concepts now understood.

\section{THE STUDY GROUP}

This study describes the re-design of a teaching plan to incorporate ongoing assessment, specifically use of the One Minute Paper, with a group of learners who were meeting Financial Management concepts for the first time. The AC4440 module is an elective 5-credit module open to all those in the final (fourth) year of study on the Bachelor of Commerce European Degree Programme, in University College Cork. The overarching goal and approach is to introduce students to key elements or concepts in financial management, scaffolding the gap between theory and application/practice of business finance in the context of real-life financial decision making and facilitating students in constructing their own knowledge and meaning of financial paradigms. The module seeks to bridge a gap between 'received knowing' and 'constructed knowing' by supporting students in a re-introduction to financial contexts and problems that they experience themselves in their daily lives (experiential learning). Module delivery is consistent with the dictates of an established modular protocol yet seeks to move beyond that by drawing on or fostering students' skills and a capacity for critical thinking that may have been developed in earlier years of their programme. Students take a number of business subjects comprising approximately half of the total credits for the programme, the balance of credits being taken in language, which may be Irish, French, German, Spanish or Italian. The third year of the programme is spent studying abroad; students then return to UCC for their final year before graduation.

Students on the programme have their first and only exposure to Financial Management concepts by taking the AC4440 5-credit module as an elective in their final year. In consequence, no prior exposure to or substantial interest in financial or corporate issues can be assumed by the lecturer/guide/moderator of the elective. A number of problems had been identified with the module by departmental staff, namely that it has traditionally been taken by relatively few students across the programme, attendance has been poor and those taking the module on average have not performed very well in the context of end-of-year university examinations, which themselves are problematic in the context of teaching and assessing for understanding. These issues motivated me in large measure to engage in this interactive learning experiment. It was clear that no assumptions could be made or solid prior conceptions held about likely attendance levels, attention spans or application rates. It was equally clear that one could hope realistically only to touch on the subject, a focus on more complete coverage would be simply inappropriate. I was curious about these issues, keen to try something new and excited at the prospect of perhaps being able to shed some light on why this might be the case, 
TABLE I: DESCRIPTION OF THE STUDY GROUP

\begin{tabular}{lcc}
\hline Programme & Number & Percentage of All \\
\hline B.Comm. French & 2 & 10 \\
B.Comm. German & 4 & 20 \\
B.Comm. Irish & 6 & 30 \\
B.Comm. Italian & 1 & 5 \\
B.Comm. Spanish & 6 & 30 \\
Erasmus & 1 & 5 \\
Total & 20 & 100 \\
\hline
\end{tabular}

through direct interaction with learners both in the lecture hall and in tutorial/ office hour environments. Reflection, both in-action and on-action, potentially offered rich scope to facilitate deep learning and new understandings and optimisation of the learning journey for these students.

The study group is represented by those taking the elective module in the academic year October 2006-June 2007. Table 1 shows the breakdown of these students.

In the study group all learners had come directly to third level from secondary schools, approximately half the student cohort derived from Cork city schools, the remainder from the Munster/South Lenister area. There was just one visiting Erasmus student and no mature student or learner from the access programme. All language options were represented, thus the AC4440 study group can be seen to be diverse.

\section{ANALYSIS OF FINDINGS}

As a 5-credit module, the AC4440 subject involves 24 direct contact hours over the 2 teaching periods of the academic year and 1 additional 'pre-examination' meeting at the terminal point. Allowing for the introductory session at the beginning of Teaching Period 1, a (formal, graded) interim assessment at the beginning of Teaching Period 2 and, at my own discretion, a 'review' session at the end of each teaching period, this implied ten 'teaching sessions' in each teaching period. With due consideration to flexibility and the likelihood of not having fully developed a particular learning goal at the conclusion of each and every lecture meeting, it was expected that in total, students would complete the OMP assessment approximately 10-15 times over the academic year as a whole. In the event, they completed 12 OMPs. Operationally, completion of the OMPs was simple and straightforward. At the end of each lecture (or relevant topic) students were given a sheet with the two questions on it, and these were completed quite literally in the last minute(s) of the class and returned to me. Students were told at the introductory session that every major topic would be subject to an OMP so they were prepared to complete it and understood the purposes for which it was sought.

The hour immediately following each lecture meeting was devoted to reading learner responses and to compiling two lists, the first list containing those 'things 
The One Minute Paper and Assessment Innovation at Third Level

understood' and the second list detailing those 'puzzles remaining'. A mental tally was kept of the number of times that particular items or concepts were appearing, in particular under the 'puzzles remaining' heading. The third component of the personal feedback sheet was titled 'action to be taken', which was filled in following a reflection on action, that action being the teaching enactment of the day. This third component addressed how the teaching plan would be amended for the following meeting to revisit the areas that constituted 'unknowing' for students, to better draw them into the concept, and to overcome the barriers to understanding. The changes made to my teaching practice depended in large measure on the concepts that were problematic for students. Table 2

TABLE 2: PERSONAL FEEDBACK SHEET RELATING TO OMP COMPLETIONS

\begin{tabular}{|c|c|c|}
\hline Areas Understood & Problematic Topics & Action to be Taken \\
\hline $\begin{array}{l}\text { Investment consumption } \\
\text { trade-off }\end{array}$ & $\begin{array}{l}\text { Graphical illustration of transfer } \\
\text { of wealth over time }\end{array}$ & $\begin{array}{l}\text { Include additional numerical } \\
\text { examples in teaching notes } \\
\text { with direct meaning for } \\
\text { students }\end{array}$ \\
\hline Investment net cashflows & Hurdle rates & $\begin{array}{l}\text { Produce simple examples } \\
\text { where variable project risks } \\
\text { have economic consequences }\end{array}$ \\
\hline $\begin{array}{l}\text { Assumption of constant } \\
\text { capital market } \\
\text { rate of interest }\end{array}$ & $\begin{array}{c}\text { Variable rate interest } \\
\text { bearing accounts }\end{array}$ & $\begin{array}{l}\text { Description of typical personal } \\
\text { mortgages in an environment } \\
\text { of changing interest rates }\end{array}$ \\
\hline $\begin{array}{l}\text { Inflation and nominal } \\
\text { rates of return }\end{array}$ & $\begin{array}{l}\text { Determining real rates } \\
\text { of return }\end{array}$ & $\begin{array}{l}\text { Illustration of 'under the } \\
\text { mattress' example and } \\
\text { maintaining purchasing power }\end{array}$ \\
\hline $\begin{array}{l}\text { Concept of Standard } \\
\text { Deviation }\end{array}$ & $\begin{array}{l}\text { Use of Standard Deviation as } \\
\text { a measure of risk }\end{array}$ & $\begin{array}{l}\text { Fuller exposition of the } \\
\text { assumptions that underlie use } \\
\text { of financial variables and their } \\
\text { distribution(s). Illustration of } \\
\text { the Normal Curve }\end{array}$ \\
\hline $\begin{array}{l}\text { Capital budgeting } \\
\text { analysis }\end{array}$ & $\begin{array}{l}\text { Extent of knowledge required } \\
\text { of factors that impact on the } \\
\text { capital budgeting technique }\end{array}$ & $\begin{array}{l}\text { Re-clarification of desired } \\
\text { learning outcomes for } \\
\text { this topic }\end{array}$ \\
\hline Risk concept & Specific versus market risk & $\begin{array}{l}\text { Identification of typical risks in } \\
\text { each category }\end{array}$ \\
\hline $\begin{array}{l}\text { Portfolio Theory } \\
\text { generally, diversifi- } \\
\text { cation of some risks }\end{array}$ & $\begin{array}{l}\text { Why market risk cannot } \\
\text { be diversified away }\end{array}$ & $\begin{array}{l}\text { Identification of risks that affect } \\
\text { all firms regardless of } \\
\text { operations, to some extent }\end{array}$ \\
\hline $\begin{array}{l}\text { Beta as measure of } \\
\text { firm exposure to } \\
\text { market risk }\end{array}$ & Portfolio beta & $\begin{array}{l}\text { Completion of additional } \\
\text { examples of calculating } \\
\text { portfolio beta as weighted } \\
\text { average across all individual } \\
\text { securities in the portfolio }\end{array}$ \\
\hline $\begin{array}{l}\text { Dividend influence } \\
\text { on price }\end{array}$ & P/E Model & $\begin{array}{l}\text { Return to market ratings } \\
\text { discussion with elaboration }\end{array}$ \\
\hline
\end{tabular}


Barnes

reproduces a portion of my personal feedback sheet together with some of the feedback obtained from students.

In many cases, including a broad number of practical real-life examples allowed learners sufficient entry points to engage with a topic or topics, and of course this was consistent with students' stated learning objective of studying a topic with a real-life, practical focus. Surprisingly, and in contrast to the extant literature, completion rates for the OMP exceeded 90 per cent consistently throughout the two teaching periods, and there was no fall off in completion, suggesting that students found the tool to be helpful and that there was no significant boredom factor with its use. I considered this consistently high completion rate a clear measure of the effectiveness of the OMP, as perceived by students, in developing learning. In terms of my own perceptions of its effectiveness, I could see students coming to a new sense of meaning about previously problematic areas of learning and therefore felt validated in amending my teaching design to achieve Biggs' (1999) constructive alignment with core objectives and stated learning outcomes.

In terms of formal assessment and student performance, all but one student attained honours in the terminal assessment and, over the group as a whole, 50 per cent attained first honours standard, a significant improvement on performance in the module in earlier years. While improvements in performance cannot unambiguously be attributed to use of the OMP - other variables such as quality of student, attendance, etc. being potentially influential in this regard - use of the OMP was certainly useful to students and informative to myself as teacherpractitioner in terms of obtaining student feedback in a timely and relevant fashion. The perception that use of the OMP was helpful to students was tested by asking students to complete an end-of-year feedback sheet, which addressed such questions as whether learning objectives had been achieved, whether module content had been perceived to be relevant and engaging and how the teaching design and enactment had been viewed. 19 students out of the group (95 per cent) returned these feedback sheets. Their responses indicated widespread satisfaction with the content of the module and the way in which that content had been explored, and demonstrated that the learning experience as a whole had reached or even exceeded student expectations. Students were particularly positive about the OMP and how its completion influenced teaching enactment at subsequent teaching interactions, which is consistent with their observed practice of voluntarily signing the OMPs. One comment read as follows, 'I really felt that we were consulted about learning and that our views were taken on board, both in what we could understand and what we couldn' $t^{\prime}$. Another student noted that, '[w]e felt acknowledged and valued and that we were part of the module plan'. One student said, '[i]t was exciting to be part of something new, an experiment where we were the beneficiaries'. Learners clearly appreciated that participation in this form of assessment could make a difference to teaching practice and to how they might best learn. Although the study group was self-selecting so that participants could be assumed to have a pronounced interest in optimising learning outcomes, nevertheless from a teaching and learning perspective this student feedback reinforced and validated the decision to take a student-centred approach, to 
emphasise frequent and consistent assessment and feedback, and to very deliberately include learners in the teaching enactment.

Moving forward with use of the OMP, I would do much the same but a small number of things differently. Electronic completion of the OMP would certainly be more time efficient in terms of gathering feedback information, however having to log on specifically to submit feedback might bias against completion rates. I would certainly devote more time at the introductory session to discussion of the learning paradigm and to the potential for optimising learning by participating in the process. I would also ask students for their thoughts on the regularity of completion of the OMP, in order to optimise its effectiveness.

\section{CONCLUSION}

In light of the sum total of feedback received, it is considered that the decision to explore the use of CATs with the AC4440 group of learners was validated, that this student-centred approach was supportive of deep meaningful learning for students and, critically, informative for myself as a lecturer. The practice of very deliberately including learners in the teaching enactment was rewarded by a ready flow of feedback from them, which constituted a win-win position, and the behavioural changes that could be seen to have been made to my teaching enactment were, in my opinion, matched by behavioural changes by learners. With respect to future teaching practice, I received substantial notice of the importance of communicating fully and clearly with students in respect of desired learning outcomes, and an indication that if I continued to explain to students that by participating in CATs they helped me to help them reach greater understandings, then that communication would likely be rewarded by consistent participation and a sharing of responsibility for learning between teacher and students. In summary, the experience was a positive one for the teacher and the student body; an experience that, I believe, represents important new evidence on the efficacy of the use of CATs at tertiary level in an Irish university context and offers the potential to inform teaching practice in a more pervasive way, if this evidence is disseminated. Early findings from a survey circulated throughout the disciplines in UCC on use of the OMP, preparatory to this self-study, suggests that the OMP is neither well known nor widely applied, although a number of queries and requests for information on the CAT give reason to believe that with sufficient explanation, there is a body of teacher-practitioners that is well-disposed towards its future use.

In terms of the extant literature and teaching practice generally, there are several important implications of this case study. Firstly, small scale, easily accessible classroom assessment techniques are useful to teachers in implementing assessments to fit their purposes and contexts. Secondly, these assessments help to make possible teacher inquiries into a domain of research needing investigation: that is, how one knows what students have learned and know how to do. This possibility also makes possible research projects that can be built on one another. It is important to note the proviso that improvements in documented performance observed for this study group cannot be simply translated into improved performance for 
Barnes

all, the influences on performance being many and varied, and that the simple technique utilised here is not necessarily so easily applied in all learning environments. Nevertheless, it is hypothesized that the use of assessment techniques that teachers can implement may improve their practice and may help to foster a new interconnection of research and practice in the everyday experiences of teachers.

\section{REFERENCES}

Almer, E.D., Jones, K. and Moeckel, C.L. (1998). The Impact of One Minute Papers on Learning in an Introductory Accounting Course, Issues in Accounting Education, Vol. 13, No. 3, pp. 485-497.

Angelo, T.A. and Cross, K.P. (1993). Classroom Assessment Techniques: A Handbook for College Teachers, San Francisco, CA: Jossey-Bass Publishers.

Berry, A. (2004). Self Study in Teaching about Learning, in J.J. Loughran and T.L. Russell (eds), International Handbook of Self Study of Teaching and Teacher Education Practices Part II, New York, NY: Routledge.

Biggs, J. (1999). Teaching for Quality Learning at University, Buckingham: Society for Research into Higher Education and Open University Press.

Biggs, J. (2003). Aligning Teaching and Assessment to Curriculum Objectives, research paper, Imaginative Curriculum Project, LTSN Generic Centre.

Bok, D. (2006). Our Underachieving Colleges: A Candid Look at How Much Students Learn and Why They Should be Learning More, Princeton, NJ: Princeton University Press.

Chizmar, J.F. and Ostrosky, A.L. (1998). The One Minute Paper: Some Empirical Findings, Journal of Economic Education, Vol. 29, No. 1, pp. 3-10.

Cochran-Smith, M. and Zeichner, K. (eds) (2005). Studying Teacher Education: Report of the AERA Panel on Research and Teacher Education, Washington, DC: American Educational Research Association (AERA) and Lawrence Erlbaum Associates.

Kuh, G.D. (2007). Risky Business: Promises and Pitfalls of Institutional Transparency, Change, September/October, Vol. 39, No. 5, pp. 30-35.

Kuh, G.D., Kinzie, J., Schuh, J.H., Whitt, E.J. and Associates. (2005). Student Success in College: Creating Conditions That Matter, San Francisco, CA: Jossey-Bass Publishers.

Kuhn, D. (2005). Education for Thinking, Cambridge, MA: Harvard University Press.

Lyons, N., Hyland, A. and Ryan, N. (2002). Advancing the Scholarship of Teaching and Learning through a Reflective Portfolio Process, Cork: UCC Press.

McElroy, B.W. and Coman, C.L. (2002). Writing to Learn in Managerial Accounting Classrooms: Further Evidence About Student Performance and Perception, Business Quest, <http://www.westga.edu/ bquest/2002/writing.htm> [accessed 19 February 2009].

Shulman, L. (2007). Counting and Recounting: Assessment and the Quest for Accountability, Change, January/February, Vol. 39, No. 1, pp. 20-25.

Stead, D.R. (2005). A Review of the One Minute Paper, Active Learning in Higher Education, Vol. 6, No. 2, pp. 118-131.

Teichler, U. (2007). Does Higher Education Matter? Lessons from a Comparative Graduate Study, European Journal of Education, Vol. 42, No. 1, pp. 11-34.

Zeichner, K. (2005). A Research Agenda for Teacher Education, in M. Cochran-Smith and K. Zeichner (eds), Studying Teacher Education: The Report of the AERA Panel on Research and Teacher Education, Washington, DC: American Educational Research Association and Lawrence Erlbaum Associates. 